\title{
Correction to: Ultrasound enhanced activation of peroxydisulfate by activated carbon fiber for decolorization of azo dye
}

\author{
Tianyin Huang ${ }^{1} \cdot$ Ke Zhang $^{1} \cdot$ Yajie Qian ${ }^{2} \cdot$ Cong Fang ${ }^{1} \cdot$ Jiabin Chen ${ }^{1,3}$ \\ Published online: 12 April 2018 \\ (C) Springer-Verlag GmbH Germany, part of Springer Nature 2018
}

\section{Correction to: Environ Sci Pollut Res \\ https://doi.org/10.1007/s11356-018-1442-3}

The corect name of the $5^{\text {th }}$ Author is Jiabin Chen.

The original article has been corrected.

The online version of the original article can be found at https://oi.org/ $10.1007 / \mathrm{s} 11356-018-1442-3$

$\triangle$ Jiabin Chen

chenjiabincn@163.com

1 School of Environmental Science and Engineering, Suzhou University of Science and Technology, Suzhou 215009, People's Republic of China

2 College of Environmental Science and Engineering, Donghua University, Shanghai 201620, People's Republic of China

3 Xiamen UrbanWater Environmental Eco-Planning and Remediation Engineering Research Center (XMERC), Xiamen, People's Republic of China 